\title{
Human GM3 Synthase Attenuates Taxol-Triggered Apoptosis Associated with Downregulation of Caspase-3 in Ovarian Cancer Cells
}

\author{
Su Huang1, Khadijeh Bijangi-Vishehsaraei ${ }^{1}$, Mohammad Reza Saadatzadeh ${ }^{2}$, Ahmad R. Safa ${ }^{{ }^{*}}$ \\ ${ }^{1}$ Department of Pharmacology and Toxicology, Indiana University Simon Cancer Center, Indianapolis, USA; ${ }^{2}$ Department of Medi- \\ cine, Division of Hematology/Oncology, Indiana University School of Medicine, Indianapolis, USA. \\ Email: ${ }^{*}$ asafa@iupui.edu
}

Received July $3^{\text {rd }}, 2012$; revised August $7^{\text {th }}, 2012$; accepted August $18^{\text {th }}, 2012$

\begin{abstract}
Background: Taxol (paclitaxel) inhibits proliferation and induces apoptosis in a variety of cancer cells, but it also upregulates cytoprotective proteins and/or pathways that compromise its therapeutic efficacy. Materials and Method: The roles of GM3 synthase ( $\alpha 2,3$-sialyltransferase, ST3Gal V) in attenuating Taxol-induced apoptosis and triggering drug resistance were determined by cloning and overexpressing this enzyme in the SKOV3 human ovarian cancer cell line, treating SKOV3 and the transfectants (SKOV3/GS) with Taxol and determining apoptosis, cell survival, clonogenic ability, and caspase-3 activation. Results: In this report, we demonstrated that Taxol treatment resulted in apoptosis which was associated with caspase-3 activation. Taxol treatment upregulated the expression of human GM3 synthase, an enzyme that transfers a sialic acid to lactosylceramide. Moreover, we cloned the full-length GM3 synthase gene and showed for the first time that forced expression of GM3 synthase attenuated Taxol-induced apoptosis and increased resistance to Taxol in SKOV3 cells. Conclusions: GM3 synthase overexpression inhibited Taxol-triggered caspase-3 activation, revealing that upregulation of GM3 synthase prevents apoptosis and hence reduces the efficacy of Taxol therapy.
\end{abstract}

Keywords: Ovarian Cancer; Taxol; GM3 Synthase; Apoptosis; Caspase-8; Drug Resistance

\section{Introduction}

Epithelial ovarian cancer is the major cause of death in women with gynecological malignancies [1]. Taxol is one of the most active cancer chemotherapeutic agents known and is effective against several human malignancies, including ovarian cancer [2,3]. Taxol promotes microtubule (MT) assembly, which produces a change in MT dynamics that disrupts the reorganization of the microtubule network required for mitosis and cell proliferation [4]. As a result, cells treated with Taxol are arrested in the $G_{1}$ and $G_{2} / M$ phases of the cell cycle [5]. Taxol triggers apoptosis in ovarian cancer cells, but also upregulates cytoprotective proteins and/or pathways that compromise its therapeutic efficacy [6,7]. Moreover, defects in apoptotic signals contribute to drug resistance in ovarian cancer [8]. Strategies to lower the threshold for triggering cancer cell apoptosis may lead to new and more effective therapeutic regimens for ovarian cancer. Therefore, targeted therapeutics against the Taxol-induced cytoprotective signals may offer a rational strategy

\footnotetext{
"Corresponding author.
}

to improve the anticancer efficacy of Taxol.

Sialyltransferases (ST) play a role in a variety of biological processes, including cell-cell communication, cell-matrix interaction, adhesion, and protein targeting [9-11]. Six human $\alpha 2,3$-sialyltransferase genes, hST3Gal I-VI, have been cloned. These multiple genes encode enzymes with closely related catalytic specificities but different patterns of tissue expression [12]. It was reported that the mRNA and activity levels of a member of the ST family, $\alpha 2,3$-sialyltransferase ST3Gal V (GM3 synthase) [13], positively correlated with resistance to the synthetic retinoid $\mathrm{N}$-(4-hydroxyphenyl)-retinamide [14] in A2780 human ovarian carcinoma cells. Moreover, Noguchi et al. [15] established GM3 synthase overexpressing cells by transfecting the cDNA of GM3 synthase into a GM3-deficient subclone of the $3 \mathrm{LL}$ Lewis lung carcinoma cell line and demonstrated that these cells were resistant to apoptosis induced by etoposide and doxorubicin by upregulating Bcl-2 expression in these cells. The acquisition of anticancer drug resistance by transfecting the GM3 synthase cDNA into these cells was associated with selective attenuation of both 
caspase- 9 and caspase- 3 , indicating that the antiapoptosis signaling effect of GM3 synthase could be involved upstream of caspase-9 [15]. Recent data revealed that elevated mRNA levels of GM3 synthase positively correlate with a high risk of pediatric acute leukemia [16]. Moreover, GM3 synthase silencing suppressed lung metastasis in murine breast cancer cells [17]. Interestingly, the GM3 synthase gene is a biomarker for histological classification as well as drug sensitivity against epidermal growth factor receptor (EGFR) tyrosine kinase inhibitors in non-small cell lung cancer [18]. Additionally, insulin resistance, a membrane microdomain disorder, depends on increased ganglioside GM3 biosynthesis following upregulated GM3 synthase gene expression [19].

The roles of GM3 synthase in Taxol resistance or apoptosis triggered by this anticancer agent have not been delineated. In this project, we explored whether Taxol treatment increased the expression of GM3 synthase in SKOV3 human ovarian cancer cells, and whether forced expression affected the sensitivity of these cells to apoptosis, thereby altering the efficacy of Taxol therapy.

\section{Materials and Methods}

\subsection{Cell Culture and Taxol Treatment}

The human SKOV3 ovarian cell line was purchased from American Type Culture Collection (ATCC, Rockville, MD). Cells were maintained in RPMI1640 media (Mediatec, Inc., Herndon, VA) supplemented with $10 \%$ fetal bovine serum (FBS) at $37^{\circ} \mathrm{C}$ in $5 \% \mathrm{CO}_{2}$. Generally, $2 \times$ $10^{5}$ cells/well were plated in six-well plate and incubated overnight. The next day, $100 \mathrm{nM}$ Taxol dissolved in dimethylsulfoxide (DMSO) were added into the indicated wells, and an equal amount of DMSO was added into control wells. The final concentration of DMSO was less than $0.1 \%$. At $48 \mathrm{~h}$ after treatment, cells were col- lected for apoptosis analysis.

\subsection{Cloning the GM3 Synthase Gene}

To clone the full-length GM3 synthase gene, we used the GM3 synthase sense primer

5'-GACATGGCTTCTGTTCCAAT-3' and the GM3 synthase antisense primer

5'-TGTTCAAAATTCACGATCAATGCC-3' to amplify the coding region of the GM3 synthase gene in SKOV3 cells by PCR. The full-length GM3 synthase DNA fragment was separated on $1.5 \%$ agarose gel and purified by a gel extraction kit (Qiagene \#28704). The purified GM3 synthase DNA fragment was subcloned into the pEF6/ V5-His TOPO expression vector (Invitrogen Corp., Carlsbad, CA) following the protocol provided by the company. Four $\mu \mathrm{L}$ of gel-purified PCR product, $1 \mu \mathrm{L}$ reaction salt buffer, and $1 \mu \mathrm{L}$ TOPO vector were mixed gently and incubated at room temperature for $5 \mathrm{~min}$. Two $\mu \mathrm{L}$ of the reaction mixture were added into a vial of ONE SHOT top 10 chemically competent $E$. coli and mixed gently. This mixture was kept on ice for $30 \mathrm{~min}$, and then this mixture was heat shocked at $42^{\circ} \mathrm{C}$ for $30 \mathrm{sec}$. After heat shock, the vial was immediately transferred onto ice. Then, $250 \mu \mathrm{L}$ of room temperature SOC medium were added to the vial. The vial was capped tightly and shaken horizontally at $200 \mathrm{rpm}$ for one $\mathrm{h}$ at $37^{\circ} \mathrm{C}$. Ten to $50 \mu \mathrm{L}$ of transformed $E$. coli were spread onto an ampicillin selective plate. The obtained GM3 synthase clones were further confirmed by DNA sequence analysis.

\subsection{Establishing a Stable SKOV3 Cell Line with Exogenous GM3 Synthase Gene}

SKOV3 cells were grown in a 6-well plate $\left(2 \times 10^{5}\right.$ cells/well) overnight. The human ovarian SKOV3 cells were transfected with the GM3/V5-His plasmid or empty pEF/V5-His plasmid by using lipofectamine 2000 transfection reagent according to the manufacturer instructtions (Invitrogen). For cell transfection in each well, 5 $\mu \mathrm{L}$ lipofectamine 2000 were added into $250 \mu \mathrm{L}$ OptiMEM serum reduced medium, and $4 \mu \mathrm{g}$ plasmid DNA were added into another $250 \mu \mathrm{L}$ Opti-MEM serum reduced medium. Each mixture was vortexed briefly and kept at room temperature for $5 \mathrm{~min}$, then the mixtures were combined and kept at room temperature for $20 \mathrm{~min}$. Five hundred $\mu \mathrm{L}$ of the mixture were then added evenly into a well of a 6-well plate; the plate was then shaken gently to thoroughly mix the transfection reagent and plasmid mix. Stable clones were obtained through screening transfected cells by adding $10 \mu \mathrm{g} / \mathrm{mL}$ Blastacidin (Invitrogen) to the growth medium at $24 \mathrm{~h}$ after transfection. After 2 - 4 weeks of growth, over-expression of GM3 synthase in the transfectants was confirmed by Western blot analysis using V5 antibody. The confirmed transfectants were expanded and stored for future studies.

\subsection{RNA Isolation and RT-PCR}

Total RNA was isolated using the RNeasy Mini Kit (Qiagen, Valencia, CA) as described by the manufacturer. Two $\mu \mathrm{g}$ of total RNA were used in reverse transcription reactions with M-MLV reverse transcriptase and oligo (dT) 15 primer (Promega, Madison, WI) as described by the manufacturer. One $\mu \mathrm{L}$ oligo-dT 15 primer, $1 \mu \mathrm{L}$ $\mathrm{dNTP}$, and $2 \mu \mathrm{g}$ total RNA were mixed and the total reaction volume was brought to $18 \mu \mathrm{L}$ by adding nuclease-free water. The reaction mixture was kept at $70^{\circ} \mathrm{C}$ for $10 \mathrm{~min}$, and then the mixture was immediately transferred onto ice. Then, $5 \mu \mathrm{L} 5 \times$ reaction buffer, $1 \mu \mathrm{L}$ M-MLV reverse transcriptase, and $0.5 \mu \mathrm{L}$ nuclease inhibitor were added into the mixture, and the total $25 \mu \mathrm{L}$ reaction volume was reached by adding nuclease-free 
water. This reaction mixture was kept at $42^{\circ} \mathrm{C}$ for $1 \mathrm{~h}$ for cDNA synthesis, followed by $70^{\circ} \mathrm{C}$ for $15 \mathrm{~min}$ to deactivate M-MLV reverse transcriptase. Four $\mu \mathrm{L}$ of the resulting total cDNA were then used as the template in PCR to measure the mRNA level of interest using the designed primers for GM3 synthase: sense,

5'-AAAGGAAACCCTGCCATTCT-3'; antisense,

5 '-TCACCACTCCCTCTTTGACC-3', $\beta$-actin mRNA levels were used as internal controls. The sense primer for actin amplification is

5'-GCCCCCCTGAACCCCAAGGCCAAC-3'. The antisense primer for actin amplification is

5'-CCGGTCGGCCGTGGTGGTGAAGCT-3'. Four $\mu \mathrm{L}$ total cDNA, $1 \mu \mathrm{L}$ (5 pmol) primer, and $12.5 \mu \mathrm{L}$ Gotaq Green Master Mix (Promega \#M7122) were mixed and a total $25 \mu \mathrm{L}$ reaction volume was reached by adding 6.5 $\mu \mathrm{L}$ nuclease-free water. The reactions were performed with denaturation at $95^{\circ} \mathrm{C}$ for $55 \mathrm{sec}$, annealing at $55^{\circ} \mathrm{C}$ for $55 \mathrm{sec}$, and extension at $72^{\circ} \mathrm{C}$ for $2 \mathrm{~min}$ for a total of 30 cycles. The amplified fragments were separated on $1.5 \%$ agarose gel and visualized under ultraviolet light by ethidium bromide staining.

\subsection{Cell Survival Assay}

The cell survival assay was performed as we previously described [20]. Cells were treated with $10-500 \mathrm{nM}$ of Taxol for $48 \mathrm{~h}$. After harvesting the cells, survival was determined by cell survival assay. For each treatment, 1 $\times 10^{4}$ cells were seeded into a 96-well plate and treated with or without $\mathrm{CMH}$. Cells were stained with $1 \%$ methylene blue in $50 \%$ methanol. After the plates were washed with PBS, the dye was dissolved in $100 \mu \mathrm{L}$ of 0.5 $\mathrm{M} \mathrm{HCl}$. Absorbance was determined by an automated scanning photometer at a wavelength of $630 \mathrm{nM}$.

\subsection{Annexin V Ainding Assay for Detecting Early Apoptotic Cells}

Following treatment as stated above, the cells $\left(5 \times 10^{5}\right.$ cells/treatment) were used to determine the translocation of phosphatidylserine to the outer surface of the plasma membrane during apoptosis using the annexin $\mathrm{V}$ binding assay. For this assay, the cells were incubated with Taxol as described above, harvested, and stained with fluorescein isothiocyanate-labeled annexin V (BD Biosciences, San Jose, CA) and propidium iodide according to the manufacturer protocol. All harvested cells were washed two times with PBS then suspended in $300 \mu \mathrm{L}$ annexin $\mathrm{V}$ binding buffer. For each sample, $100 \mu \mathrm{L}$ cell suspension, $5 \mu \mathrm{L}$ annexin V FITC-conjugated antibody and $1 \mu \mathrm{L} 250 \mu \mathrm{M}$ propidium iodide were mixed and kept in darkness place at room temperature for $30 \mathrm{~min}$. Then, another $400 \mu \mathrm{L}$ of annexin $\mathrm{V}$ binding buffer were added into each sample for final flow cytometry analysis.
Apoptosis and necrosis were analyzed by quadrant statistics on the propidium iodide (PI)-negative, fluoresceinpositive cells, and PI-positive cells, respectively.

\subsection{Detection of Apoptosis by DAPI Staining}

DAPI staining was performed on untreated and Taxoltreated cells as described previously [20]. Briefly, prior to staining, the cells were fixed with $4 \%$ paraformaldehyde for $30 \mathrm{~min}$ at room temperature. After washing with PBS by centrifugation at $650 \times \mathrm{g}$, DAPI was added to the fixed cells for $5 \mathrm{~min}$, then the cells were examined by fluorescence microscopy. Apoptotic cells were identified by condensation and fragmentation of nuclei. A minimum of 300 cells were counted for each treatment, and the percentage of apoptotic cells was calculated as the ratio of apoptotic cells to total cells counted $\times 100$.

\subsection{Clonogenic Assay}

Clonogenic assay was carried out as we previously described [21]. SKOV3 cells were transfected with EF6 or GM3Syn-EF6 expression vector, treated with or without 5 or $10 \mathrm{nM}$ Taxol for $48 \mathrm{~h}$, and after washing the cells with growth media lacking Taxol, they were grown for 7 days. The colonies in control or Taxol-treated wells were then counted. Error bars represent the standard deviation for each point obtained from triplicate experiments.

\subsection{Western Blot Analysis}

In this study, the following primary antibodies were used: anti-caspase-3 (Cell Signaling Technology, Danvers, MA), anti-V5 antibody (Invitrogen Corp., Carlsbad, CA), anti- $\beta$-actin clone AC-74 (Sigma-Aldrich, St. Louis, MO). Protein concentrations were determined by using the $\mathrm{BCA} / \mathrm{Cu}_{2} \mathrm{SO}_{4}$ protein assay (Sigma-Aldrich) as described by the manufacturer. For Western blot analysis, $50-80$ $\mu \mathrm{g}$ protein/lane were separated by $12 \%$ SDS-PAGE, blotted onto a PVDF Immobilon membrane, and then protein levels were detected using peroxidase-conjugated secondary antibodies as described by the manufacturer. The primary antibody was used at a concentration of 1:2000 (v/v). The membranes were then exposed to Kodak X-Omat film for various times. The mouse monoclonal anti- $\beta$-actin (clone AC-74) was purchased from Sigma-Aldrich and used at 1:5000 (v/v).

\section{Results}

\subsection{GM3 Synthase Is Induced during Taxol-Induced Apoptosis}

We have found that Taxol at $100-500 \mathrm{nM}$ induces robust apoptosis in cell lines from different types of cancer [22]. As shown in Figure 1(a), the annexin V binding assay revealed that Taxol at $100 \mathrm{nM}$ induced early apop- 


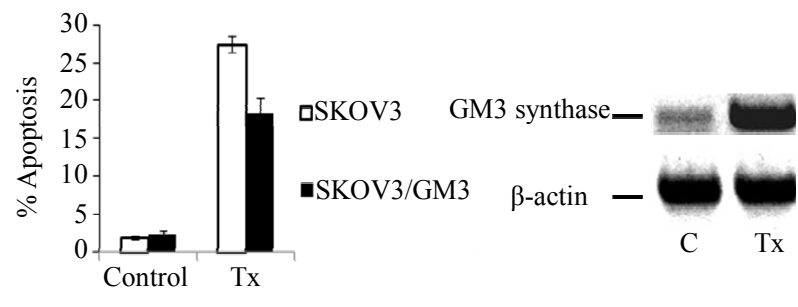

(a)
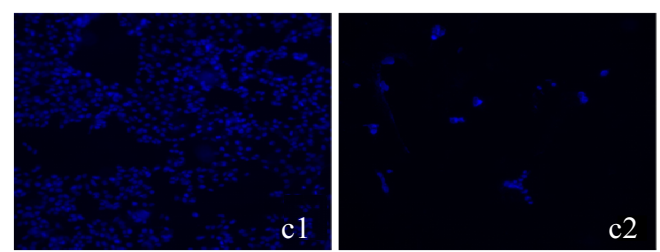

c3

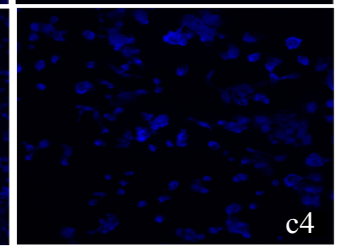

(c)

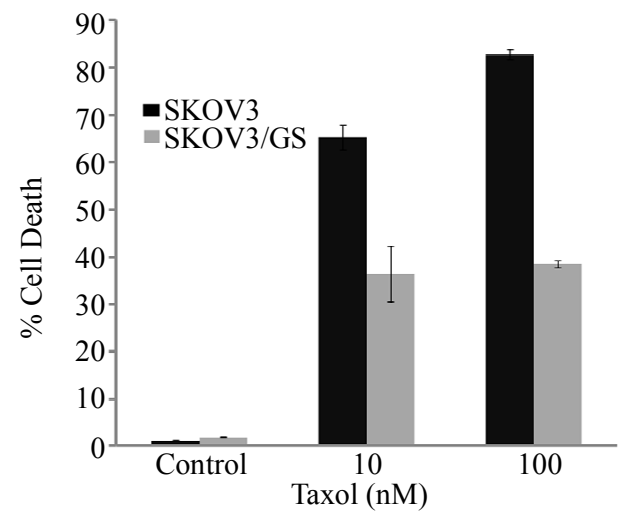

(d)

Figure 1. Taxol-induced apoptosis and GM3 synthase expression in SKOV3 cells. (a) Cells were treated with $100 \mathrm{nM}$ Taxol for $48 \mathrm{~h}$, harvested, and apoptosis was determined by FACS analysis as described in Materials and Methods. Compensation was executed for each experiment using untreated cells and cells stained only with annexin $\mathrm{V}$ or propidium iodide, respectively. Error bars show standard deviation from triplicate measurements ( $\left.{ }^{*} \mathbf{P}<0.05\right)$; (b) Total RNA from SKOV3 cells was extracted and the levels of GM3 synthase mRNA were measured by RT-PCR. $\beta$-actin was used as an internal control in the RT-PCR reactions; (c) SKOV3 and SKOV3/GS cells were treated with $100 \mathrm{nM}$ of Taxol for $48 \mathrm{~h}$ and apoptotic cell death was determined by DAPI staining as described in Materials and Methods (c1 and $c 3$ are control untreated SKOV3 and SKOV3/GS, respectively; c2 and c4 SKOV3 and SKOV3/GS cells treated with $100 \mathrm{nM}$ Taxol, respectively); (d) Apoptotic cells were identified by condensation and fragmentation of nuclei. A minimum of 300 cells were counted for each treatment, and the percentage of apoptotic cells was calculated. Error bars show S.D. from triplicate measurements. tosis in $28 \%$ of SKOV3 cells, and RT-PCR analysis showed that while SKOV3 cells express little GM3 synthase at the mRNA level, it was significantly increased after Taxol treatment (Figure 1(b)). These data suggest that Taxol induces GM3 synthase expression.

\subsection{Expression of GM3 Synthase Decreases Taxol-Induced Apoptosis in SKOV3 Cells}

To determine the role of GM3 synthase in Taxol-induced apoptosis, we constructed a GM3 synthase III-EF6 plasmid and transfected SKOV3 cells. Stable SKOV3 transfected populations harboring this plasmid contained elevated levels of GM3 synthase as determined by immunoblot analysis (Figure 2). As revealed by annexin V binding assay, treating SKOV3 cells with $100 \mathrm{nM}$ Taxol for $48 \mathrm{~h}$ induced early apoptosis in $28 \%$ - 30\% of the cells, as compared to $17 \%$ in transfectants overexpressing GM3 synthase (SKOV3/GS) (Figures 1(a) and (b)). These results show that the overexpression of GM3 synthase reduces early apoptosis triggered by Taxol in SKOV3/GS cells $(\mathrm{P}<0.05)$. Next, we determined the levels of late apoptosis induced by Taxol in SKOV3 and SKOV3/GS cells by DAPI staining. Apoptotic cells were identified by condensation and fragmentation of nuclei. The data shown in Figures 1(c) and (d) clearly show that Taxol induced apoptosis as visualized by DAPI staining of these cells treated with 10 - $100 \mathrm{nM}$ Taxol. Quantitation of apoptosis assessed by DAPI staining revealed that treating the cells with $10-100 \mu \mathrm{M}$ Taxol for $48 \mathrm{~h}$ induced $60 \%-80 \%$ apoptosis in SKOV3 cells, but only

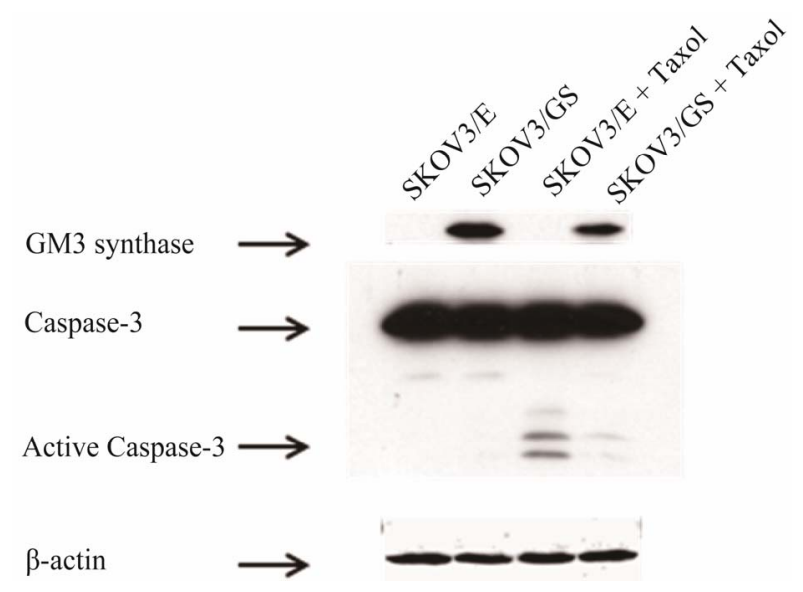

Figure 2. GM3 synthase prevents caspase-3 activation. Western blot analysis of GM3 synthase expression in SKOV3/GS cells using V5 antibody. SKOV3 and SKOV3/ GS cells were treated with $100 \mathrm{nM}$ Taxol for $48 \mathrm{~h}$ and GM3 synthase was detected by Western blot analysis using V5 antibody as described in the Material and Methods. Note that forced expression of GM3 synthase attenuates Taxol-induced apoptosis (Figure 1(a)) and caspase-3 activation. 
triggered 35\% - 38\% apoptosis in SKOV3/GS cells, indicating that GM3 synthase overexpression attenuates late Taxol-induced apoptosis.

To determine whether overexpression of GM3 synthase in SKOV3 transfectants increases cell proliferation, we determined number of cells after $48 \mathrm{~h}$ of culturing as described in Materials and Methods. As shown in Figure 3(a), GM3 synthase-overexpressing cells displayed 20\%

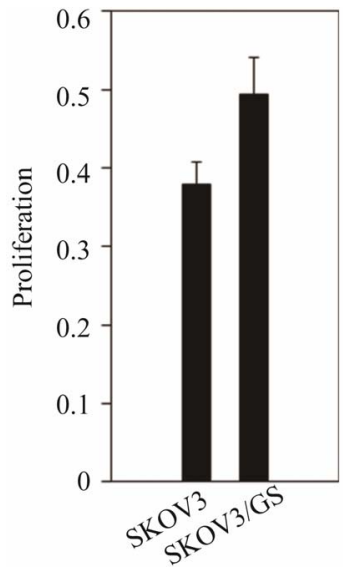

(a)

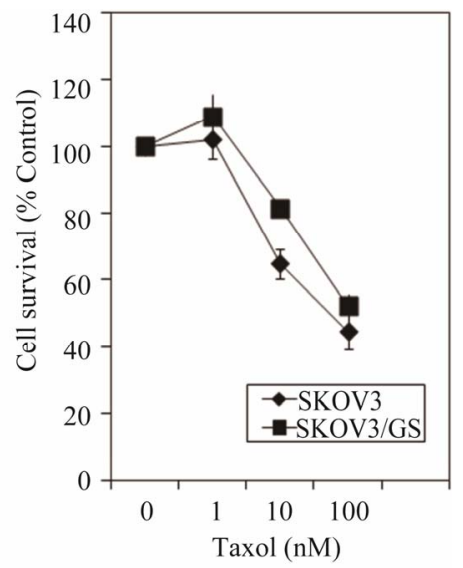

(b)

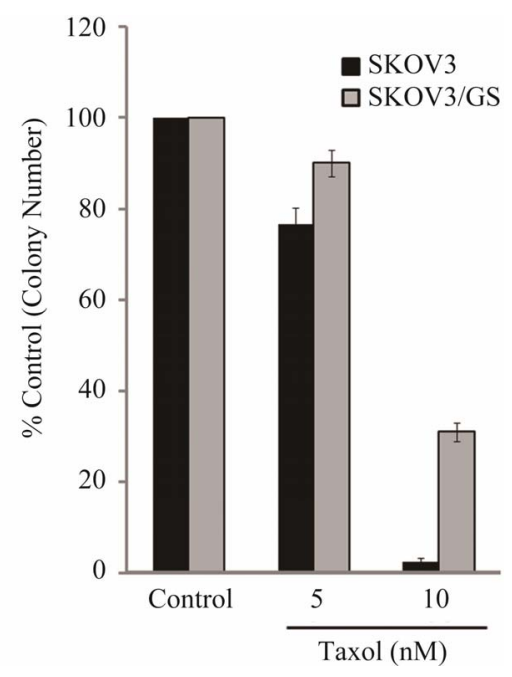

(c)

Figure 3. GM3 synthase increases proliferation and decreases Taxol cytotoxicity in SKOV3/GS cells. (a) SKOV3 and SKOV3/GS cells were grown for $48 \mathrm{~h}$ and the number of cells was determined as described in Materials and Methods; (b) SKOV3 and SKOV3/GS cells were treated with 1 - $100 \mathrm{nM}$ Taxol for $48 \mathrm{~h}$ and the numbers of cells which survived was determined by methylene blue cytotoxicity assay as described in Materials and Methods; (c) SKOV3 cells untreated and SKOV3 cells treated with 5 or $10 \mathrm{nM}$ Taxol for $48 \mathrm{~h}$; SKOV3/GS untreated cells and SKOV3/GS cells treated with 5 or $10 \mathrm{nM}$ Taxol for $48 \mathrm{~h}$ as described in the Materials and Methods. Colonies were counted 7 days later. The values are representative of triplicate counts and error bars show standard deviations. increased proliferation compared to SKOV3 cells. Moreover, to determine whether Taxol decreases cell survival to the same extent in SKOV3 and GM3 synthase-overexpressing SKOV3/GS cells, we treated these cells with increasing concentrations of Taxol and determined cell survival by methylene blue cell survival assay as described in Materials and Methods. The results shown in Figure 3(b) revealed that SKOV3/GS survived cells are about 2 - 3-fold more resistant to Taxol than SKOV3 cells.

To examine whether GM3 synthase-overexpressing cells exhibited resistance to Taxol, we executed a colony forming assay. Clonogenic assay was carried out as described in Materials and Methods. As shown in Figure 3(c), more colonies were survived in SKOV3/GS cells compared to SKOV3 cells following treatment with 5 and $10 \mathrm{nM}$ Taxol.

We also examined the role of caspase- 3 in Taxol-induced apoptosis in SKOV3 and SKOV3/GS cells, since it is a central caspase in the mitochondrial apoptotic signaling pathway. SKOV3 cells were treated with Taxol and caspsase-3 levels were analyzed by immunoblotting. As shown in Figure 2(a), Taxol induced the processing of caspase-3 to its active forms, revealing that caspase-3 is involved in mediating Taxol death signals. While the results shown in Figure 2 demonstrated that Taxol induced processing of procaspase- 3 to its active forms, the ectopic expression of GM3 synthase inhibited this process, and barely active caspase- 3 forms were detected expressing GM3 synthase. These data clearly show that GM3 synthase functions as an endogenous caspase-3 inhibitor in SKOV3 cells.

\section{Discussion}

Our previous results showed that Taxol-induced apoptosis in SKOV3 ovarian cancer cells is associated with caspase- $8,-9$, and -3 activation in these cells [22]. Despite cytoreductive surgery and primary chemotherapy, advanced epithelial ovarian cancer is a highly lethal malignancy [23]. Usually, following an initial high response rate, the patient relapses and the tumor acquires resistance to chemotherapy. Defects in apoptotic signaling pathways contribute to drug resistance in ovarian cancer $[24,25]$. In the search to identify novel cytoprotective signaling molecules which attenuate Taxol-triggered apoptosis, we found for the first time that GM3 synthase expression was upregulated in Taxol-treated SKOV3 cells. Furthermore, we found that increased expression of GM3 synthase served a cytoprotective function, prevented early and late Taxol-induced apoptosis, and was associated with caspase- 3 activation.

GM3 synthase is a member of the sialyltransferase family which catalyzes ganglioside GM3 biosynthesis. 
Gu et al. [17] demonstrated that GM3 synthase silencing suppressed lung metastasis in murine breast cancer cells. Conversely, compared to wild-type cells, stable overexpression of sialyltransferase-1 (SAT-1, GM3 synthase) or pharmacological manipulation of A2780 human ovarian cancer cells with $\mathrm{N}$-(4-hydroxyphenyl) retinamide had elevated ganglioside levels, reduced in vitro cell motility, and enhanced expression of the membrane adaptor protein caveolin-1 [26]. In GM3 synthase-overexpressing clones, both depletion of gangliosides by treatment with the glucosylceramide synthase inhibitor D-threo-1-phenyl2-decanoylamino-3-morpholino-1-propanol and silencing of caveolin-1 by siRNA increased in vitro cell motility [27].

To our knowledge, this is the first report describing the role of GM3 synthase in attenuating Taxol-induced cell death and causing resistance to this agent in SKOV3 cells. Previous work has shown that transfection with GM3 synthase in a GM3-deficient clone derived from a murine Lewis lung carcinoma cell line increased colony formation and resistance to apoptosis [15]. Moreover, GM3 synthase-deficient lymphoid cells underwent Fas-induced apoptosis [28]. Interestingly, recent results by Ohkawa et al. [29] also showed that Wisp2/CCN5, a member of the $\mathrm{CCN}$ family proteins involved in cell proliferation, angiogenesis, tumorigenesis, and wound healing, was upregulated in nervous tissues in GM3-only mice. Furthermore, Wisp2/CCN5-overexpressing cells were resistant to apoptosis induced by $\mathrm{H}_{2} \mathrm{O}_{2}$. Our study suggests that GM3 synthase as an anti-apoptotic protein may be of value as a therapeutic target in various cancers, and could also serve as a diagnostic marker for identifying drugresistant tumors.

Identifying the critical apoptosis regulatory molecular targets of Taxol in cancer cells may lead to improved cancer therapy regimens that utilize a lower dose of Taxol, thereby limiting systemic toxicities. Moreover, identifying novel cytoprotective molecules such as GM3 synthase capable of preventing Taxol-triggered apoptosis validates these molecules as rational targets to sensitize cancers to Taxol death signals. Investigating these targets and their roles in Taxol-induced apoptosis will also provide novel information on the specific signaling pathways involved in this process, which could be useful for discovering drugs with greater selectivity and efficacy. The molecular mechanism of upregulating GM3 synthase by Taxol and how it decreases caspase- 3 activation are of great interest. Furthermore, strategies to reduce the expression of GM3 synthase and/or inhibit its activity by small molecule inhibitors are likely to render cancer cells more sensitive to Taxol-induced apoptosis.

\section{Acknowledgements}

We would like to thank Dr. Mary D. Kraeszig for her editorial assistance. This work was supported by research grants W81XWH-07-1-0410 and RO1 CA 101743 from the Department of Defense (DOD) and the National Cancer Institute, respectively, to A.R.S.

\section{REFERENCES}

[1] M. Daly and G. I. Obrams, "Epidemiology and Risk Assessment for Ovarian Cancer," Seminars in Oncology, Vol. 25, No. 3, 2008, pp. 255-264.

[2] J. Crown, M. O'Leary and W. S. Ooi, "Docetaxel and Paclitaxel in the Treatment of Breast Cancer: A Review of Clinical Experience," Oncologist, Vol. 9, Suppl. 2, 2004, pp. 24-32. doi:10.1634/theoncologist.9-suppl 2-24

[3] A. L. Fields and C. D. Runowicz, "Current Therapies in Ovarian Cancer," Cancer Investigation, Vol. 21, No. 1, 2003, pp. 148-156. doi:10.1081/CNV-120016409

[4] M. A. Jordan and L. Wilson, "Microtubules as a Target for Anticancer Drugs," Nature Reviews Cancer, Vol. 4, No. 4, 2004, pp. 253-265. doi:10.1038/nrc1317

[5] P. C. Liao and C. H. Lieu, "Cell Cycle Specific Induction of Apoptosis and Necrosis by Paclitaxel in the Leukemic U937 Cells," Life Sciences, Vol. 76, No. 14, 2005, pp. 1623-1639. doi:10.1016/j.lfs.2004.09.021

[6] Y. Fu, D. Hu, J. Qiu, X. Xie, F. Ye and W. G. Lu, “Overexpression of Glycogen Synthase Kinase-3 in Ovarian Carcinoma Cells with Acquired Paclitaxel Resistance," International Journal of Gynecological Cancer, Vol. 21, No. 3, 2011, pp. 439-444. doi:10.1097/IGC.0b013e31820d7366

[7] Y. Tian, A. C. Tan, X. Sun, M. T. Olson, Z. Xie, N. Jinawath, D. W. Chan, L. M. Shih, Z. Zhang and H. Zhang, "Quantitative Proteomic Analysis of Ovarian Cancer Cells Identified Mitochondrial Proteins Associated with Paclitaxel Resistance," Proteomics Clinical Applications, Vol. 3, No. 11, 2009, pp. 1288-1295. doi:10.1002/prca.200900005

[8] D. Mezzanzanica, E. Balladore, F. Turatti, E. Luison, P. Alberti, M. Bagnoli, M. Figini, A. Mazzoni, F. Raspagliesi, M. Oggionni, S. Pilotti and S. Canevari, "CD95-Mediated Apoptosis Is Impaired at the Receptor Level by Cellular FLICE-Inhibitory Protein (Long Form) in WildType p53 Human Ovaian Carcinoma," Clinical Cancer Research, Vol. 10, No. 15, 2004, pp. 5202-5214. doi:10.1158/1078-0432.CCR-03-0537

[9] A. Fukuda, "Possible Roles of Tumor-Associated Carbohydrate Antigens," Cancer Research, Vol. 56, No. 10, 1996, pp. 2237-2244. doi:10.1158/1078-0432.CCR-03-0537

[10] E. L. Kean, A. K. Münster-Kühnel and R. Gerardy-Schahn, "CMP-Sialic Acid Synthetase of the Nucleus," Biochimica et Biophysica Acta, Vol. 1673, No. 1-2, 2004, pp. 56-65. doi:10.1016/j.bbagen.2004.04.006

[11] F. Dall'Olio and M. Chiricolo, "Sialyltransferases in Cancer." Glycoconjugate Journal, Vol. 18, No. 11-12, 2001, pp. 841-850. doi:10.1007/s10719-007-9078-4

[12] A. Taniguchi, "Promoter Structure and Transcriptional 
Regulation of Human Beta-Galactoside Alpha2, 3-Sialyltransferase Genes," Current Drug Targets, Vol. 9, No. 4, 2008, pp. 310-316. doi:10.2174/138945008783954998

[13] H. J. Choi, T. W. Chung, N. Y. Kang, K. S. Kim, Y. C. Lee and C. H. Kim, "Involvement of CREB in the TranScriptional Regulation of the Human GM3 Synthase (hST3Gal V) Gene during Megakaryocytoid Differentiation of Human Leukemia K562 Cells," Biochemical and Biophysical Research Communications, Vol. 313, No. 1, 2004, pp. 142-147. doi:10.1016/j.bbrc.2003.11.103

[14] A. Prinetti, L. Basso, V. Appierto, M. G. Villani, M. Valsecchi, N. Loberto, S. Prioni, V. Chigorno, E. Elena Cavadini, F. Formelli and S. Sonnino "Altered Sphingolipid Metabolism in N-(4-Hydroxyphenyl)-retinamideresistant A2780 Human Ovarian Carcinoma Cells," The Journal of Biological Chemistry, Vol. 278, No. 8, 2003, pp. 5574-5583. doi:10.1074/jbc.M207269200

[15] M. Noguchi, K. Kabayama, S. Kang, B. W. Uemura, M. Saito, Y. Igarashi and J. Inokuchi, "Endogenously Produced Ganglioside GM3 Endows Etoposide and Doxorubicin Resistance by Up-Regulating Bcl-2 Expression in 3LL Lewis Lung Carcinoma Cells," Glycobiology, Vol. 16, No. 8, 2006, pp. 641-650. doi:10.1074/jbc.M207269200

[16] S. Mondal, S. Chandra and C. Mandal, "Elevated mRNA Level of hST6Gal I and hST3Gal V Positively Correlates with the High Risk of Pediatric Acute Leukemia," Leukemia Research, Vol. 34, No. 4, 2010, pp. 463-470. doi:10.1016/j.leukres.2009.07.042

[17] Y. Gu, J. Zhang, W. Mi, J. Yang, F. Han, X. Lu and W. $\mathrm{Yu}$, "Silencing of GM3 Synthase Suppresses Lung Metastasis of Murine Breast Cancer Cells," Breast Cancer Research, Vol. 10, No. 1, 2008, p. R1. doi:10.1186/bcr1841

[18] M. Noguchi, T. Suzuki, K. Kabayama, H. Takahashi, H. Chiba, M. Shiratori, S. Abe, A. Watanabe, M. Satoh, T. Hasegawa, S. Tagami, A. Ishii, M. Saitoh, M. Kaneko, K. Iseki, Y. Igarashi and I. Inokuchi, "GM3 Synthase Gene is a Novel Biomarker for Histological Classification and Drug Sensitivity against Epidermal Growth Factor Receptor Tyrosine Kinase Inhibitors in Non-Small Cell Lung Cancer," Cancer Science, Vol. 98, No. 10, 2007, pp. 1625-1632. doi:10.1111/j.1349-7006.2007.00578.x

[19] J. Inokuchi, "Physiopathological Function of Hematoside (GM3 Ganglioside)," Proceedings of the Japan Academy —Series B: Physical \& Biological science, Vol. 87, No. 4, 2011, pp. 179-198. doi:10.2183/pjab.87.179

[20] K. Bijangi-Vishehsaraei, M. R. Saadatzadeh, S. Huang, M. P. Murphy and A. R. Safa, "4-(4-Chloro-2-methylphenoxy)N-hydroxybutanamide (CMH) Targets mRNA of the c-FLIP Variants and Induces Apoptosis in MCF-7 Human Breast Cancer Cells," Molecular and Cellular Biochemistry, Vol. 342, No. 1-2, 2010, pp. 133-142.

\section{doi:10.1007/s11010-010-0477-7}

[21] T. W. Day, S. Huang and A. R. Safa, "c-FLIP Knockdown Induces Ligand-Independent DR5-, FADD-, Caspase-8-, and Caspase-9-Dependent Apoptosis in Breast Cancer Cells," Biochemical Pharmacology, Vol. 76, No. 12, 2008, pp. 1694-1704. doi:10.1016/j.bcp.2008.09.007

[22] S. Huang, T. W. Day, M. R. Choi and A. R. Safa, "Human $\beta$-Galactoside Alpha-2,3-Sialyltransferase (ST3Gal III) Attenuated Taxol-Induced Apoptosis in Ovarian Cancer Cells by Downregulating Caspase-8 Activity," Molecular and Cellular Biochemistry, Vol. 331, No. 1-2, 2009, pp. 81-88. doi:10.1007/s11010-009-0147-9

[23] M. A. Bookman, "First-Line Chemotherapy in Epithelial Ovarian Cancer," Clinical Obstetrics and Gynecology, Vol. 55, No. 1, 2012, pp. 96-113. doi:10.1097/GRF.0b013e31824b45da

[24] M. Fraser, B. Leung, A. Jahani-Asl, X. Yan, W. E. Thompson and B. K. Tsang, "Chemoresistance in Human Ovarian Cancer: The Role of Apoptotic Regulators," Reproductive Biology and Endocrinology, Vol. 1, 2003, pp. 66. doi:10.1186/1477-7827-1-66

[25] A. Richardson and S. B. Kaye, "Drug Resistance in Ovarian Cancer: The Emerging Importance of Gene Transcription and Spatio-Temporal Regulation of Resistance," Drug Resistance Updates, Vol. 8, No. 5, 2005, pp. 311321. doi:10.1016/j.drup.2005.09.001

[26] A. Prinetti, M. Aureli, G. Illuzzi, S. Prioni, V. Nocco, F. Scandroglio, N. Gagliano, G. Tredici, V. Rodriguez-Menendez, V. Chigorno and S. Sonnino, "GM3 Synthase Overexpression Results in Reduced Cell Motility and in Caveolin-1 Upregulation in Human Ovarian Carcinoma Cells," Glycobiology, Vol. 20, No. 1, 2010, pp. 62-77. doi:10.1093/glycob/cwp143

[27] A. Prinetti, T. Cao, G. Illuzzi, S. Prioni, M. Aureli, N. Gagliano, G. Tredici, V. Rodriguez-Menendez, V. Chigorno and S. Sonnino, "A Glycosphingolipid/Caveolin-1 Signaling Complex Inhibits Motility of Human Ovarian Carcinoma Cells," The Journal of Biological Chemistry, Vol. 286, No. 47, 2011, pp. 40900-40910. doi: $10.1074 /$ jbc.M111.286146

[28] I. Popa, N. Therville, S. Carpentier, T. Levade, O. Cuvillier and J. Portoukalian, "Production of Multiple BrainLike Ganglioside Species is Dispensable for Fas-Induced Apoptosis of Lymphoid Cells," PLoS One, Vol. 6, No. 5, 2011, p. e19974. doi:10.1371/journal.pone.0019974

[29] Y. Ohkawa, Y. Ohmi, O. Tajima, Y. Yamauchi, K. Furukawa and K. Furukawa, "Wisp2/CCN5 Up-Regulated in the Central Nervous System of GM3-Only Mice Facilitates Neurite Formation in Neuro2a Cells via Integrin-Akt Signaling," Biochemical and Biophysical Research Communications, Vol. 411, No. 5, 2011, pp. 483-489. doi:10.1016/j.bbrc.2011.06.118 